\title{
A interpretação econômica da lei tributária e o fato gerador do Imposto Provisório sobre Movimentação Financeira
}

\section{Carlos Klein Zanini}

Graduado pela Faculdade de Direito da UFRGS

Mestrando em Direito Comercial pela Faculdade do Largo São Francisco - USP

\section{SUMÁRIO}

I. O fato gerador do IPMF - análise do art. $2^{\circ}$ da Lei Complementar n⿳0 77/93; II. A interpretação da Lei Tributária com base no critério econômico; III. A utilização do cretério econômico pelo art. $2^{\circ}$, inciso V, da L.C. nº 77/93 e o direito brasileiro; IV. Da inadequação da interpretação à luz do critério econômico ao direito brasileiro. Do Princípio Constitucional da Legalidade Tributária; V. Conculusões.

A motivação para escrever este artigo surgiu à partir de leituras de obras que versam sobre o complexo tema da interpretação da lei tributária. Foi assim, justamente, a parti da reflexão sobre o conteúdo destes textos e, muito especialmente, do excelente prefácio do Prof. Brandão Machado à monografia de Wilhelm Hartz: Interpretação da Le Tributária - que nos ocorreu a idéia de esboçar este singelo estudo, onde procuramos aplicar esses conhecimentos teóricos apreendidos na análise de um caso prático, a qual submetemos, agora, à opinião dos doutos.

I. O fato gerador do I.P.M.F. - análise do art. $2^{\circ}$ da Lei Complementar no 77/93.

Após sucessivas publicações e republicações, logrou êxito o Governo Federal na instituição do I.P.M.F. no ordenamento jurídico-tributário pátrio. Tem-se, portanto mais um imposto a figurar no já tão extenso rol de imposiçōes fiscais a onerar os brasileiros. Não é, contudo, escopo deste artigo, voltar críticas à condução da Política Fiscal da União, tampouco a esta modalidade de imposto. ${ }^{1}$ Pelo contrário. Nossa in tenção ao elaborá-lo cinge-se, unicamente, à análise das questōes jurídicas trazidas à reflexão com a instituição dessa nova exação
V) qualquer outra movimentação ou transmissão de valores e de créditos e direitos de natureza financeira que, por sua finalidade, reunindo características que permitam presumir a existência de sistema organizado para efetivá-la, produza os mesmos efeitos previstos nos incisos anteriores, independentemente da pessoa que a efetue, da denominação que possa ter e da forma jurídica ou dos instrumentos utilizados para realizá-la.

Da redação desse artigo, transparece, com clareza, a intenção do legislador ao nele inserir o texto contido em seu inciso quinto. Pretendeu, através desse dispositivo, obstar a elisão fiscal, impedindo os cidadãos de escapar à incidência do imposto pela utilização de outras operações que não as descritas nos incisos anteriores.

Cabe, no entanto, ante a amplitude, abrangência e imprecisão deste inciso quinto, levantar a seguinte questão: não conteria esse inciso orientação no sentido da interpretação fundada em critério econômico? Seria tal dispositivo compatível com o princípio da estrita legalidade, informador do sistema tributário nacional? É, portanto, em torno dessas indagações que desenvolveremos nossa dissertação.

II. A interpretação da Lei Tributária com base no critério econômico

A utilização do critério econômico na interpretação da lei tributária é fenômeno relativamente recente no campo do direito, tendo surgido na Alemanha, sob inspiração de Enno Becker - insigne integrante do Superior Tribunal Administrativo. A gênese deste verdadeiro novo método de interpretação das leis tributárias deu-se, como sucede com todas as criações do direito, a partir de uma demanda histórica, ou seja, de uma adaptação do direito aos reclamos da vida em sociedade.

Assim, quando Becker foi encarregado, em 1919, da elaboração de um Código Tributário Alemão, partiu da observação de que o Estado necessitava, àquela época, mais do que nunca - após o término da 1a. Guerra Mundial -, de normas tributárias que garantissem de forma austera o ingresso das divisas necessárias à recuperação da Nação. Observara também que os contribuintes, habilmente, evitavam a incidência das leis fiscais, elegendo para celebração de seus negócios formas de direito privado diversas daquelas descritas, abstratamente, na hipótese de incidência dos comandos impositivos ${ }^{3}$.

Dessa forma, a partir dessa constatação e da placitação serena que os tribunais alemães emprestavam às manobras (lícitas) dos contribuintes, tendentes a economizar impostos, Becker viu-se compelido a inserir na lei - que estava incumbido de formular - um preceito que, expressamente, recomendasse ao intérprete e aplicador da lei não só a observância dos elementos jurídicos constantes da norma, mas, além disto, que atentâsse à real intenção e aos efeitos - em termos econômicos - pretendidos pelas partes ${ }^{4}$.

Percebe-se, nesse ponto, a compulsória filiação de Becker à corrente doutrinária dos subjetivistas, porquanto era-lhe indispensável - a fim de viabilizar a adoção do critério econômico na interpretação das leis - que defendesse, acima de tudo, a verdadei ra intenção do legislador ${ }^{5}$. Foi, destarte, com base no método teleológico de interpretação que Becker desenvolveu os dois preceitos basilares do Código de 1919, e que, por permitirem ao leitor uma visualização mais nítida de suas concepções, merecem ser transcritos: "Parágrafo $4: \mathrm{Na}$ interpretação das leis tributárias, devem se considerados a sua finalidade, o seu significado econômico e o desenvolvimento das circunstâncias. Parágrafo 5: A obrigação tributária não pode ser elidida ${ }^{6}$ ou reduzida mediante o emprego abusivo de forma formulações de direito civil. (...)".

Evidentemente, não é nosso propósito e nem caberia aqui discorrer sobre as críticas que foram fomuladas à teoria do critério econômico, tal qual positivada no direito alemão por Enno Becker. Nossa preocupação, neste breve estudo, reside em demonstrar não as vicissitudes que estão a macular este método interpretativo, mas sim seus contornos gerais, de forma que se possa 
deixar clara sua absoluta inaplicabilidade no sistema do direito tributário brasileiro.

Tais considerações fazem-se sobremaneira importantes à luz do disposto no inciso V, do artigo $2^{\circ}$ da L.C. $77 / 93$, dantes referido, que, a toda evidência, pretende inserir em nosso ordenamento o critério econômico de valoração dos fatos, para fazer incidi a lei tributária.

Vejamos, por conseguinte, no que consiste este critério econômico, para que possamos, a seguir, demonstrar o intuito desse dispositivo da Lei Complementar 77/93, e quais os princípios constitucionais pátrio que repudiam sua aplicação em nosso sistema jurídico.

Pois bem, doutrina Wilhelm Hartz, em sua obra Interpretação da Lei Tributária, que o critério econômico pode ser utilizado como princípio de valoração, ou seja, na "apreciação de um acontecimento concreto, real, relativamente às suas conseqüências tributárias"7. Dessa forma, cumpriria ao aplicador da norma tributária atentar não só à estrita hipótese de incidência nela contida, mas, principalmente, aos fins colima dos pelo legislador ao instituí-la, alcançando, por conseguinte, outros fatos de mesmo significado econômico, porém não previstos expressamente em sua prótase. $\mathrm{E}$, em linhas gerais, o que dispõe ainda hoje o Código Tributário Alemão de 1977: Parágrafo 42: A lei tributária não pode ser fraudada através do abuso de formas jurídicas. Sempre que ocorrer abuso, a pretensão do imposto surgirá, como se para os fenômenos econômicos tivesse sido adotada a forma jurídica adequada".

Depreende-se, desse dispositivo, que a utilização do critério econômico autoriza o aplicador da lei tributária a flexibilizá-la ampliando sua área de atuação para além daqueles fatos descritos na hipótese de incidência da norma, e que, uma vez ocorridos em concreto, ensejam, automaticamente, sua incidência. Vê-se, portanto, que con soante o critério econômico, importante é compreender os fatos em sua acepção econômica, ou seja, preferindo os verdadeiros efeitos visados pelas partes à adoção dest ou daquela forma jurídica. É o que preleciona W. Hartz: "Casos com o mesmo apoio econômico recebem o mesmo tratamento tributário. O que pode ser decisivo para a tributação não é o que está no papel, pois o que está escrito com frequência no papel tem objetivo apenas fiscal, mas é, sim, o que as partes efetivamente quiseram e realizaram" ${ }^{\prime 8}$.

A propósito, encontramos na monografia do Prof. Sampaio Dória, Elisão e Evasão Fiscal, exemplificação que bem ilustra a forma pela qual se aplica o critério econômico. Refere o autor, ao comentar o direito tributário alemão, que nele havia um imposto sobre a venda e que certo contribuinte, pretendendo vender seu automóvel em parcelas, celebrou contrato de locação do veículo, evitando, assim, a incidência da imposição9. Ora, tal simulação revela, de modo saliente, a total incompatibilidade entre a intenção do contribuinte - denominada de intentio facti - e a correspondente intentio juris, pela eleição de uma forma jurídica completamente atípica e desvinculada dos fins pretendidos pelas partes. Nesta hipótese, se aplicado o critério econômico, esta "locação" seria considerada - para fins de incidência - como autêntica compra e venda, muito embora não adotada a forma jurídica típica à esta modalidade negocial (contrato de compra e venda), e, que, normalmente, acarretaria a incidência do imposto sobre vendas.

Resta, assim, evidenciado que a aplicação do critério econômico dá-se, justamente, sobre fatos que, a priori, não seriam capazes de determinar a incidência da norma impositiva, porque não se encontrariam previstos na sua hipótese de incidência. A utilização desse critério teria como objetivo traze para o âmbito de abrangência do comando normativo todos aqueles fatos que, normalmente, dele escapariam. Em assim sendo, verifica-se que a sua utilização resulta numa maximização da efetividade da norma juridica, dotando-a de uma maleabilidade incomum, que jamais poderia ser atingida pela descrição precisa, na hipótese legal, de fatos aptos a determinarem sua incidência. $A$ área de atuação deste método interpretativo en- contra-se, portanto, traçada fora do círculo de fatos previstos abstratamente pela norma pois estes a ela já se subsumem, naturalmente, pelo fenômeno jurídico da incidência.

III. A utilização do critério econômico pelo art. $2^{\circ}$, inciso V, da L.C. 77/93 e o direito brasileiro

Após termos exposto, sinteticamente, como se dá a utilização do critério econômico no direito alemão e no que esse consiste, podemos agora voltar a atenção sobre o dispositivo acima mencionado, examinando a possibilidade de sua inserção no direito pátrio. Não restam dúvidas de que a mens legislatoris, ao incluir esse último inciso dentre os que estabelecem o fato gerador do I.P.M.F., não foi outra senão a de impossibilitar a elisão fiscal de recursos movimentados pelos contribuintes fora das previsões legais precedentes. Dessa forma, sabendo o legislador ser impossível prever todas as modalidades de transferência e movimentação de divisas, aproveitou, da doutrina alemã, o critério econômico, insculpindo-o aqui com a nítida intenção de combater a engenhosidade dos contribuintes em escapar à imposição tributária ${ }^{10}$. $\mathrm{O}$ desiderato do legislador pode ser também apreendido a partir da análise dos termos em que se encontra vazado este dispositivo, que revela, de forma cristalina, a presença do critério econômico como elemento de valoração das movimentações e transmissões realizadas pelos contribuintes, não subsumíveis às hipóteses previstas nos demais incisos. Assim, ressai a preocupação teleológica do legislador, eis que esse se preocupa mais com os fins visados pelo contribuinte - transferência de riqueza - do que com a forma jurídica por ele adotada para operacionalizá-la.

Para que se vislumbre com clareza a presença do critério econômico neste inciso basta compará-lo com o Parágrafo 42 do Código Tributário Alemão, que dispõe: "A lei tributária não pode ser fraudada através do abuso de formas jurídicas. Sempre que ocorrer abuso, a pretensão do imposto sur- girá, como se para os fenômenos econômicos tivesse sido adotada a forma jurídica adequada (i)".

Com efeito, percebe-se dos termos deste dispositivo que a sua ratio consiste em fazer incidir a norma tributária, cuja incidência foi evitada pelos contribuintes, mediante a eleição de forma diversa daquela prevista abstratamente no seu aspecto material. Ora se compararmos esse dispositivo do Código Alemão com o inciso $\mathrm{V}$, do art. $2^{\circ}$ da Le instituidora do I.P.M.F., veremos a sua similitude. Assim é que também esse dispositivo da lei brasileira se preocupa com os efeitos econômicos desejados pelos contribuintes - no caso, transferência de recursos - independentemente da forma por eles eleita para atingir essa finalidade.

O texto desse preceito é de per si suficientemente esclarecedor: "art. $2^{\circ}$ (...) - inciso V - qualquer outra movimentação ou transmissão de valores e de créditos e direitos de natureza financeira que, por sua finalidade, reunindo características que permitam presumir a existência de sistema organizado para efetivá-la, produza os mesmos efeitos previstos nos incisos anteriores, independentemente da pessoa que a efetue, da denominação que possa ter e da forma jurí dica ou dos instrumentos utilizados para realizá-la (ii).

As locuçōes grifadas demonstram, de forma inconteste, a semelhança dos dispositivos. Ambas (i) (ii) desprezam a forma jurídica eleita pelas partes, buscando, no efeito econômico desejado, a fundamentação para tornar devido o tributo ${ }^{11}$.

Todavia, como trataremos de expor a seguir, o critério econômico - tal qual positivado no inciso comentado - apresenta-se absolutamente incompativel com os princípios que integram e moldam o sistema tributário brasileiro.

IV. Da inadequação da interpretação à luz do critério econômico ao direito brasileiro. Do Princípio Constitucional da Legalidade Tributária.

Nunca é demais lembrar que o princípio da legalidade tributária, construído, histori- 
camente, a partir da reação do povo oprimido contra a voracidade fiscal dos governantes, caracteriza-se por ser um dos mais importantes princípios inspiradores dos sistemas constitucionais tributários construí dos sob o império do Estado de Direito ${ }^{12}$. $\mathrm{Em}$ nossa Constituição vigente isso não se dá diferentemente. Dedica essa dois artigos ao princípio da legalidade. $O$ primeiro de les, de caráter geral, situado no Capítulo que trata dos Direitos e Garantias Individuais - art. $5^{\circ}$, inciso II; e, o segundo, no âmbito do direito tributário, inscrito no inciso I do art. 150, que estabelece as Limitações do Poder de Tributar ${ }^{13}$. Tem-se, por conseguinte, diante do conteúdo desses artigos, que a exigência de quaisquer tributos, no ordenamento jurídico brasileiro, somente será validada caso seja percorrido o estrito caminho legal que a Carta prescreve para a imposição fiscal. Aliás, de outra forma não poderia ser, pois o atendimento ao cânon da legalidade representa a mais cara garantia dos contribuintes frente à atuação estatal, afastando-os do arbítrio ${ }^{14}$

Cabe agora indagar acerca do que representa, no contexto do sistema impositivo nacional, o princípio da legalidade tributá ria. Nesse particular, parece-nos importante ressaltar que o legislador constituinte pátrio, ao "constitucionalizar" o princípio da legalidade tributária, condicionou, expressamente, a instituição de qualquer tributo à utilização do instrumental jurídico próprio: a lei. Assim, somente por via legislativa podem os contribuintes ser coactados ao pagamento de determinada exação fiscal. Não há outra forma válida e apta a determinar a transferência dos recursos privados para o Estado que não seja através da lei. Somente a lei tem o condão de sujeita alguém ao recolhimento de um tributo ${ }^{15}$.

Contudo, para que se institua, efetivamente, determinado tributo, não basta que o diploma legal enuncie seu nomen iuris ${ }^{16}$ É imprescindível que a lei estabeleça de modo claro e preciso todos os elementos que o definam, v.g., fato imponível, hipótese de incidência, base de cálculo, alíquota sujeitos passivos, tal qual estabelece o art.
146, inciso III, da C.F. 88. Nesse sentido ensina, com maestria, Roque Carrazza: "Para afugentarmos, desde já, possíveis dúvidas, é bom dizermos que criar um tributo é descrever abstratamente sua hipótese de incidência, seu sujeito ativo, seu sujeito passivo, sua base de cálculo e sua alíquota. Em suma: é editar, pormenorizadamente, a norma jurídica tributária. Essa norma, por injunção ao princípio da legalidade, repitamos, há que ser sempre veiculada por meio de lei ordinária. Portanto, as exigências do princípio da legalidade tributária são cumpridas quando a lei delimita, concreta exaustivamente, o fato tributável"17. Se bem observado o teor das lições de Carrazza, podemos, já a partir de agora, demonstrar de forma serena, o porquê da inadaptação do inciso V do art. $2^{\circ}$ da Lei Complementar $77 / 93$ ao nosso sistema jurídico tributário e, em especial, ao princípio da legalidade tributária.

É que esse princípio postula, fundamentalmente, que todos os elementos essenciais do tributo devam estar previstos, detalhadamente, na lei. Como lembra Alberto Xavie ao enaltecer a reserva absoluta de lei formal "deve o Fisco limitar-se a subsumir o fato à norma, sem qualquer tipo de valoração" ${ }^{18}$ Do que, aliás, não destoa Pontes de Miranda, ao sustentar que o Direito Tributário possui método próprio de interpretação: "O método de fontes e de interpretação das leis tributárias não é precisamente o método de fontes e interpretação das leis comuns; e a fonte é uma só: a lei. ... Não se pode, por meio da analogia, ou de argumentos lógicos, estender o que se editou nas leis. O entendimento é rígido e estrito ${ }^{19}$. A lei tributária limita direitos, impõe deveres. Por outro lado, é da natureza das leis tributárias a precisão, pela taxatividade e pelos elementos matemáticos de que se tem de lançar mão para atingir o patrimônio das pessoas que são sujeitas às regras jurídicas tributárias" 20

Ora, a imprecisão do comando contido no atacado dispositivo legal é por demais evidente Consoante já exposto acima, tal preceito objetivou estender - valendo-se do critério econômico - a incidência do I.P.M.F. a todas as operações não abrangidas pelas hipóteses de incidência constantes da lei. Ou seja, pretendeu instituir um imposto com hipótese de incidência flexível que poderia ser ampliada com base nas finalidades econômicas de certa operação Trata-se, em resumo, de verdadeira cláusula geral de tributo, porquanto não discrime, precisamente, o aspecto material determinador de sua incidência ${ }^{21}$

Em assim sendo, resulta impossível conciliar esse dispositivo com a tipicidade estrita exigida pelo princípio constituciona da legalidade. Dessa incompatibilidade ver tical do inciso quinto com o princípio constitucional da legalidade ${ }^{22}$ - que the e hierarquicamente superior - resulta, inexoravelmente, sua absoluta inconstitucionalidade.

A título de complementação, para que reste bem demonstrada a inadaptação da interpretação com fulcro no critério econômico (tal qual prevista no dispositivo comentado) ao princípio da legalidade - e portanto, ao nosso sistema constituciona tributário, convém colacionar os ensina mentos de Hensel: "o critério econômico que o direito tributário alemão instituiu para combater a evasão fiscal e aumentar receita dos impostos ... abre caminho para 0 arbítrio, com arranhões profundos nos princí pios da legalidade e segurança jurídica" ${ }^{23}$

Por último, não se diga que, por estar albergado em Lei Complementar (L.C. $77 / 93$ ), poderia o critério econômico ser utilizado na definição dos fatos geradore do I.P.M.F., já que o art. 108 do C.T.N. que veda a exigência de tributo com base na analogia - estaria situado em norma de mesmo plano hierárquico ${ }^{24}$, logo, sujeita a regr de que a lex posterior derogat priori . Ta argumento seria aplicável unicamente ao art. 108 do C.T.N. considerado isoladamente. Contudo, o choque desse dispositivo (que propõe a utilização do critério econô mico) dá-se não com o C.T.N., mas com a Constituição Federal de 1988, que alberga o princípio da legalidade tributária. A in compatibilidade desse indigitado dispositi- vo decorre, portanto, de sua frontal ofensa à Lei Maior, depositária dos mais importan tes direitos dos cidadãos, dentre os quais destaca-se o direito à segurança jurídica, que encontra amparo, justamente, no princípio da legalidade, e que, em obra clássica, fora exaltado, magnificamente, por Georges $\mathrm{Ri}$ pert como sendo o "désir que tout bomme civilisé a dans le coeur ${ }^{125}$.

\section{V - Conclusões}

1. O artigo $2^{\circ}$, inciso V, da Lei Complementar $n^{\circ} 77 / 93$, ao eleger os fatos geradores do I.P.M.F., utiliza-se do critério econômico de interpretação e valoração dos fatos sujeitos à lei tributária, mediante emprego da analogia e observância da finalidade econômica visada pelo contribuinte em cada operação de movimentação ou transferência de recursos.

2. O critério econômico é admitido, expressamente, pelo direito alemão - onde se encontra positivado - e coaduna-se, estreitamente com a doutrina que sustenta a interpretação subjetiva das leis.

3. Esse método de interpretação das leis tributárias e valoração dos fatos é absolutamente incompatível com o artigo 108, parágrafo primeiro, do C.T.N., e bem assim com o princípio da legalidade tributária, constante do artigo 150 , inciso I, da Constituição Federal de 1988.

4. O princípio da legalidade tributária exige que a lei instituidora/reguladora do tributo, especifique, detalhadamente, com grande riqueza de detalhes, todos os elementos essenciais da norma jurídico-tributária.

5. O art. 2o, inciso V da Lei Complemen$\operatorname{tar} n^{\circ}$ 77/93, ao flexibilizar o âmbito de incidência do I.P.M.F. (mediante a utilização do critério econômico), viola, frontal mente, o princípio da legalidade tributária, estando, portanto, maculado de vícios insanáveis de inconstitucionalidade material.

6. Destarte, carece de validade o indigitado dispositivo, devendo ser aceitos como determinadores do fato gerador do I.P.M.F. somente os demais incisos constantes do 
art. 2 da Lei Complementar no 77/93, que descrevam, de forma suficientemente precisa, os fatos imponíveis aptos a ensejar quando ocorridos in concreto - sua subsunção à norma, independentemente de qualquer valoração.

Porto Alegre, março de 1994.

\section{Notas}

${ }^{1}$ Oportuno aqui referir o caráter nefasto desta exação fiscal que, taxando todos os contribuintes à mesm aliquota, tributa-os sem atender ao princípio da capa cidade contributiva, alcançando, não raras vezes, mo-
vimentaçōes financeiras despidas de qualquer elemento signo-presuntivo de riqueza (a terminologia é de Alfredo A. Beker). Vale, pois, lembrar a crítica de Thomas Powell: "clearly it , pous, len undesirable if a sN Tho "Powell: "clearly in would be undesirable if a stale sbould ROBERTO SAMPAIO DÓRIA, Direito Consting Rio Te Rio de Janeiro, p129.

${ }^{2}$ Apesar da crítica, a nosso ver procedente, que se faz à expressão "fato gerador" - que designaria duas real dades distintas (GERALDO ATALIBA in: Hipótese Incidencia Tributária, pp. 48, nr. 18.4, ed. R.T., 1990) a empregamos aqui apenas para nos manter fieis terminologia constante do

${ }^{3}$ É sempre ilustrativa a célebre frase de DUVERGER, segundo o qual "Comme une anguille le contribuable glise entre les mailles du filet législatif".

${ }^{4}$ Para maior riqueza de informaçōes, consulte-se o DO ao livro de WILHELM HARTZ, o qual procurmos aqui sintetizar.

5 Dentre os eméritos integrantes dos subjetivistas podemos citar SAVIGNY, para quem interpretar a lei sigfegislador e recapitular mentaluente a sua ativida WINDSCHEID segundo o qual a interpretaçá determinasão do sentido gue o legislador ligou ds palavia por ele utilizadas devendo o intérprete integrarse o mais possivel no espirito do legislador. Apud. ENGISCH, $\mathrm{Karl}$ Introduça ao Pensamento Juridico. ed Fundacão Ca louste Gulbenkian, 1983, Lisboa, 6a ed.

6 No orignial "eludida"

7 Wilhelm Hartz, Interpretação da Lei Tributária, ed Resenha Tributária, 1993, São Paulo, p. 95

8 op. cit., p. 97

9 Elisão e evasão fiscal, ed. José Bushatsky, 1977, São Paulo, p. 111

${ }^{10}$ Adotamos, como conceito de elisão, a clássica formulação de SAMPAIO DÓRIA para o qual é "licita a evasāo concretizada na conduta individual preventiva ir ou retardar a ocorrencia do proprio fato gerador in: Elisão e evasão fiscal, ed. José Bushatsky, 1977, São Paulo, p. 38.

11 Os defensores do critério econômico sustentam que uma de suas vantagens reside no fato desse atentar efetiva capacidade contributiva dos contribuintes, porquanto prende-se aos elementos econômicos da oper ção.

12 Já a Carta Magna de 1215, autêntico instrumento limitação do poder do Estado - representado n figura de João Sem-Terra impunha a observância do pincípio da legalidade na instituição de impostos.

Preceituam referidos dispositivos, respectivamente Ninguém será obrigado a fazer ou deixar de fazer alguma coisa senăo em virtude de lei". "Art. 150, inciso - Sem prejuizo de outras garantias asseguradas a contribuinte, e vedado d Uniăo, ... exigir ou aument

${ }^{4}$ A esse respeito, demonstrando a violência dirigida contra os particulares - Insita a todo processo de tributação - escreve WILHELM HARTZ: "O direito tribut rio e o processo de tributação atingem fundo a esfera pessoal do cidadão. Não há, talvez, outro campo do direito em que o Estado enfrente todos os cidadãos tåo amiúde e táo de perto como quem exige por força de um dircito superior, impondo-lhes a consciencia sujeição". op. cit. p. 76

${ }^{15}$ Tal corolário encontra-se expresso no brocardo nul lum vectigal sine lege.

${ }^{6}$ Aliás, é cediço na doutrina que o nomen iuris pouco significa na caracterização da exação fiscal. Este o escólio de GERALDO ATALIBA: "o nome que o legisldor atribui aos institutos jurídicos é inteiramente irro evante. Havendo ou não rigor terminológico, institutos jurídicos são aquilo que sua essencia re, E prossegue: "... o nomen iuris é um rótulo que egislador arbitrariamente apõe aos institutos que cria modela. Nesse sentido, pode-se dizer que ele é livre para dar qualquer nome aos institutos e pode inclusive como freqüentemente acontece - equivocar-se, criando institutos a que atribui designą̧ōes impróprias". GERALDO ATALIBA in: Hipótese de Incidência Tributária, p. 48, nr. 18.4, ed. R.T., 1990

17 in: Curso de direito constitucional tributário, Revista dos Tribunais, 3a. ed., São Paulo, 1991, p. 155 18 apud. ROQUE CARRAZZA. Curso de direito consitucional tributário, ed. Revista dos Tribunais, 3a. ed. São Paulo, 1991, p. 158.

19 Também neste sentido as lições de CARLOS MAXIMILIANO: "Pressupõe-se ter havido o maior cuidado ao redigir as disposiçōes em que se estabelecem impostos ou taxas, designadas em linguagem clara e precisa as pessoas e coisas alvejadas pelo tributo, bem determ nados o modo, lugar e tempo do lançamento e da cias referentes à incidência e à cobrançáa. Trata-se de norma de tal espécie como se fosse rigorosamente taxativa; deve, por isso abster-se o aplicador de the restringir ou dilatar o sentido. Muito se aproxima das penais, quanto à exegese, porque encerram prescr ções de ordem pública, imperativas ou proibitivas, fetam o livre exercicio dos direitos patrimoniais. Não suportam o recurso a analogia, nem a interpretação extensiva, as suas disposiçoes aplicam-se no sentido igoroso, estrito". in. Hermeneutica e aplicaçáa do direito, 11a. ed., ed. Forense, Rio de Janeiro, 1991, p.

in: Comentários à Constituição de 1967, tomo II página 382

21 Oportuno aqui colacionarmos os ensinamentos $d$ ALBERTO XAVIER: "A tipicidade repele assim a tri- butaçăo baseada num conceito geral ou cláusula geral de tributo, ainda que referida à ideia de capacidade econônica .... Os principios da legalidade e da tipicidade da tributação, ed. R.T., São Paulo, 1978.

22 Para KELSEN, a incompatibilidade pode dar-se em dois planos: vertical ou horizontal, conforme essa estabeleça ou não em niveis de hierarquia diversos.

23 apud Interpretação da Lei Tributária, ed. Resenha Tributária, 1993, p. 21.

24 É assente na doutrina que o C.T.N. vige hoje com eficácia de Lei Complementar, não obstante, formalmente, não o seja.

${ }^{25}$ Le Déclin du Droit, Librairie Génerale de Droit et de Jurisprudence, 1949, Paris, p. 155 